\section{PPGED}

Programa de Pós-Graduação

em Economia Doméstica www.oikos.ufv.br | ISSN: 2236-8493

revistaoikos@ufv.br
Avaliação: Double Blind Review Recebido: 25/01/2018 Aprovado: 08/08/2018

\title{
Agressão física contra a pessoa idosa: a prevalência da questão de gênero na velhice
}

\author{
Physical aggression against the old person: the prevalence of the gender issue in old age
}

Francismara Fernandes Guerra ${ }^{1}$

Karla Maria Damiano Teixeira²

\section{Resumo}

Neste trabalho, procurou-se descrever a vitimização por agressão física sofrida pelos idosos no Brasil, por meio de análise comparativa. Para tanto, utilizou-se os dados do suplemento da PNAD, de 2009, a fim de se traçar o perfil das vítimas, bem como para avaliar as chances de idosos e não idosos se tornarem vítimas de agressão física pelos modelos logísticos. Verificou-se que, apesar da população idosa não sofrer a maior incidência deste tipo de crime, ela apresenta perfil semelhante à população não idosa, quando se realiza análise por sexo. Destaca-se, sobretudo, que as principais semelhanças referem-se ao local de ocorrência do crime, ao agressor e à busca por justiça. O que denota, claramente, que a população idosa deveria ser incluída em políticas de gênero, quando se trata de vitimização.

Palavras-chave: Agressão física; Idoso; Sexo.

\begin{abstract}
In this work, we sought to describe the victimization by physical aggression suffered by the elderly in Brazil, through a comparative analysis. In order, we used data from the supplement of the PNAD of 2009 to trace the profile of the victims, as well as we evaluate the chances of the elderly and non-elderly becoming victims of physical aggression through logistic models. We verified that, although the elderly population do not suffer the highest incidence of this type of crime, it presents similar profile to the non-elderly population in an analysis by sex. We noted, above all, the main similarities are related to place of occurrence of the crime, the aggressor and the search for justice. This clearly indicates that the elderly population should be included in gender policies when it comes to victimization.
\end{abstract}

Keywords: Physical aggression; Older; Sex.

\footnotetext{
${ }^{1}$ Doutora em Demografia pela Universidade Federal de Minas Gerais. Professora do Instituto Federal de Minas Gerais (IFMG) Campus Governador Valadares. E-mail: francismarafernandes@yahoo.com.br

2 PhD em Ecologia Familiar pela Michigan State University. Professora Associada do Programa de Pós-Graduação em Economia Doméstica da Universidade Federal de Viçosa. E-mail: kdamiano@ufv.br
} 


\section{INTRODUÇÃO}

Nas últimas décadas, a vitimização da pessoa idosa ganhou grande visibilidade no meio acadêmico internacional, evidenciando a necessidade de maior discussão e análise no âmbito nacional. O tema emerge, sobretudo, quando a população mundial vivencia o chamado envelhecimento populacional, no qual se observa o aumento da expectativa de vida e o crescimento da população idosa. À despeito da causa do envelhecimento populacional, a vitimização do idoso tem sido acompanhada pelo surgimento de vários mitos. O principal mito seria de que, no passado, as pessoas mais velhas eram tratados melhor do que agora (BROGDEN; NIJHAR, 2000b). Esta visão harmoniosa do passado esconde remotas evidências de que crimes contra os idosos não são problemas que surgiram em decorrência de mudanças demográficas, por causa da desagregação da família nuclear ou pelo enfraquecimento da rede de vizinhos, mas em virtude da persistente crueldade intergeracional (REINHARZ, 1986). Sugerindo, com isso, que a vitimização não é evento novo, mas descoberta nova.

O que leva ao questionamento científico sobre qual a real situação do idoso no tocante à vitimização? Isto é, atualmente, a população idosa seria a principal vítima na sociedade? Homens idosos e mulheres idosas estão sujeitos ao mesmo risco de vitimização? Quais as principais características destes crimes? Como as vítimas procuram por justiça? Este artigo tem como objetivos elucidar estas questões, sob a perspectiva da agressão física, em análise comparativa entre idosos e não idosos, discriminada por sexo. Para isso, a metodologia empregada divide-se em estatísticas descritivas e modelos logísticos, em que utiliza-se os resultados da Pesquisa Nacional por Amostra de Domicílios (PNAD), desenvolvida pelo Instituto Brasileiro de Geografia e Estatística (IBGE), publicada em 2009, a qual investigou, em caráter suplementar, o tema no Brasil.

Estatisticamente, espera-se que com o aumento da população idosa, o número de casos de violência contra essa faixa etária também cresça. Contudo, esse tipo de estatística não é algo aceitável em um país em desenvolvimento, como o Brasil, onde os índices de segurança e de qualidade de vida deveriam estar em plena ascensão. Com isso, os dados sobre vitimização precisam ser adequadamente analisados para evitar interpretações equivocadas e nortear, de forma adequada, as políticas públicas voltadas para segurança pública e promoção de justiça. 


\section{REVISÃO DE LITERATURA}

\section{Vitimização dos idosos: uma breve abordagem}

Ao se analisar estudos prévios sobre vitimização, constata-se fraca e inconsistente definição dos objetos das pesquisas realizadas, já que as definições vêm diferindo tão amplamente de estudo para estudo. O que impõe grande dificuldade ao se tentar comparar os resultados obtidos, demandando, dessa forma, análise mais ampla dos conceitos que perpassam a vitimização. Cabe ressaltar, contudo, que este trabalho não tem pretenção de delimitar ou apresentar, de forma conclusiva, qualquer definição que aborde vitimização, apresentando, portanto, as principais vertentes estudadas que estejam relacionadas ao tema.

Para Brogden e Nijhar (2000a), o conceito de abuso considerado neste artigo, em suas diversas formas de definição, como violência física, verbal, emocional, maus tratos, coação, privação de liberdade, entre tantas outras) suscita muitas dúvidas aos criminologistas. Pois, o indivíduo rotulado como abusado é tido, muitas vezes, como incapaz. E, apesar de todos os indivíduos terem direitos iguais perante as leis, o poder, na tomada de decisões dos incapazes, é outorgado a outros. O que pode excluir os indivíduos abusados, incluindo idosos abusados, da proteção das leis e do conhecimento das autoridades. Por esse motivo, a criminologia, geralmente, ignora ou falha ao ocupar-se dos abusos cometidos contra a pessoa idosa, o que impede o registro adequado dos fatos e seu estudo acadêmico.

Além disso, sob a criminologia tradicional, os abusos são somente analisados se forem definidos legalmente, ou seja, se o ato infringe uma norma social (mas não uma lei), este não será mediado sob a perspectiva criminológica (BROGDEN; NIJHAR, 2000a). A criminologia tradicional configura-se, assim, como disciplina relativamente teórica, que falha ao atender aos anseios universais. E, como resultado desta crítica, a criminologia moderna constrói uma reformulação da problemática legal sobre crime, redefinindo-o como desvio de comportamento. Na tentativa de definir a noção flexível de desvio, entende-se como crime aquilo que é ou está infringindo a norma social. Dessa forma, o crime passa a ser construção coletiva, que não apenas corresponde ao ato em si, como também resulta da pressão social em busca das prioridades públicas, em que o abuso passa a ser sinônimo de desvio (BROGDEN; NIJHAR, 2000a).

A dificuldade de identificação dos casos de vitimização contra a pessoa idosa não se resume, somente às questões criminológicas, pois conta, ainda, com a fragilidade das informações reportadas pela população. Uma vez que os autores dos abusos são conhecidos, por estarem proximamente relacionados com os idosos, a presença de tais autores, durante o registro de sua ocorrência, pode dissuadir a declaração da vítima. Ao mesmo tempo que, idosos 
com perda cognitiva podem, por exemplo, declarar informações imprecisas. Ademais, nos casos em que não há vítima fatal, alguns idosos podem, simplesmente, não admitir sofrer abusos (WALLACE; BONNIE, 2003a).

As declarações das vítimas não se constituem a única fragilidade das informações reportadas pela população. Por um lado, os familiares, os cuidadores e as pessoas de confiança dos idosos podem ter conhecimento incompleto dos eventos. E, por outro lado, as informações declaradas por funcionários de instituições sociais, destinadas ao cuidado de idosos, apresentam, regularmente, variações quanto ao poder de observação clínica, medidas e anotações não padronizadas, coletadas, em grande parte, de forma não sistemática (WALLACE; BONNIE, 2003a).

O que se apreende sobre o processo de envelhecimento, até o momento, está preso ao imaginário social do velho vitimado, que atesta a incapacidade do velho, sempre frágil, indefeso ou caricato. Sob este discurso, o idoso não é mais um sujeito, mas um ser doente, que onera as reservas públicas da saúde e estimula o consumo de medicamentos. A vida parece ser organizada de forma segmentada, definindo estereótipos para cada faixa etária. Contudo, Novo e Lopes (2010) mostram que nossa sociedade está cercada de mitos e que nem sempre o velho é abusado, mas um sujeito com desejos e atitudes violentas.

Além disso, o abuso contra o idoso recebeu, com certa frequência, status análogo ao abuso contra a criança e o adolescente, ainda que as diferenças entre ambas as situações sejam grandes. Um menor necessita de um tutor que assegure, com autoridade, sua custódia, ao passo que um adulto é, assumidamente, competente para tomar suas próprias decisões. Isso torna as analogias dos abusos cometidos contra idosos e crianças outro mito (CRYSTAL, 1986; PAYNE, 2005).

A despeito dos mitos que envolvem a temática, Wallace e Bonnie (2003b) mostram que há fatores de risco validados por evidência substancial da literatura que podem ser identificados como fortes determinantes na exposição do idoso aos maus tratos. A coabitação, por exemplo, favorece oportunidades para o contato e propicia, deste modo, as tensões, os conflitos e, por fim, os abusos, podendo variar segundo o tipo de arranjo domiciliar. O isolamento social, como mecanismo de detecção de abuso, também sugere que seja mais provável a ocorrência de maus tratos contra idosos com redes sociais fracas, em comparação àqueles com forte redes socais.

Doenças neurodegenerativas, como o Alzheimer, e doenças mentais estão igualmente relacionadas com o risco de maus tratos contra a pessoa idosa. Entretanto, a demência não seria propriamente fator de risco, mas fator de exposição, relacionado com as reações dos cuidadores aos episódios de violência da pessoa com esse quadro. Além disso, as características individuais 
dos abusadores, como doenças mentais, hostilidade, alcoolismo, uso de drogas e dependência financeira em relação ao abusado, são fortes indicadores de provável vitimização do idoso. Dentre as motivações que impelem os quadros de violência, sobressaem-se os relacionamentos permeados de violência e os sentimentos experimentados entre as partes - agressor e agredido - como tristeza, decepção, raiva, injustiça, angústia e revolta (SILVA; DIAS, 2016). Demonstrando que o preparo emocional, principalmente das famílias, é fundamental no cuidado de idosos.

Há, ainda, possíveis fatores de risco que podem estar associados à vitimização do idoso, mas não são cientificamente comprovados (WALLACE; BONNIE, 2003b). O fator raça é um exemplo, pois são desconhecidos estudos que tenham chegado a conclusões claras sobre o assunto. Já a questão do gênero sugere que a maioria das vítimas idosas seja mulher. Contudo, ainda, não é claro tal evidência, pois a vitimização diferenciada poderia estar relacionada, realmente, com o alto risco de ocorrência ou poderia ser reflexo da grande proporção de mulher nessa faixa etária. Outro fator duvidoso refere-se ao relacionamento entre a vítima e o abusador. Há a ideia de que os filhos adultos sejam os principais abusadores dos pais idosos, entretanto também acredita-se que os abusadores mais prováveis sejam os cônjuges.

Segundo Faleiros (2010), os fatores de risco associados à vitimização, principalmente no Brasil, não podem ser reduzidos à questão da idade, pois, como mostram as taxas de mortalidade por causas externas, jovens e idosos estão suscetíveis a riscos aproximados. Isso porque, na atualidade, as condições de vida e a estrutura do capitalismo são determinantes da configuração dos paradigmas da violência, que pode ocorrer em qualquer lugar e a qualquer hora. Por isso a necessidade de se discutir a vitimização sob outras vertentes.

Destaca-se, nesse sentido, que a vitimização do idoso tem muito em comum com os abusos cometidos contra as mulheres, com exceção das causas. Ambas são associadas à violência doméstica, modelo de vitimização que assume a ocorrência de mau trato na relação adulto-adulto. Ou seja, diferentemente dos abusos contra a criança, nesta analogia, há desigualdade de poder no relacionamento, mas a vítima é racional e potencialmente capaz na determinação do fato ocorrido (BROGDEN; NIJHAR, 2000a). Neste ponto, chega-se à lacuna na literatura que, no artigo, se propõe a analisar: a vitimização do idoso sob a vertente de gênero. O que, por sua vez, irá gerar cenário mais completo daquele já descrito até então sobre a vitimização do idoso. 


\section{NOTAS METODOLÓGICAS}

Os dados utilizados, neste artigo, provêm da Pesquisa Nacional por Amostra de Domicílio (PNAD), de 2009, e de seu suplemento sobre as características da vitimização e do acesso à justiça no Brasil. A PNAD se caracteriza por uma amostragem complexa que permite a expansão dos resultados para o universo brasileiro. As variáveis estudadas incluem a ocorrência de agressão física, o agressor, o local do crime e os motivos que impediram a busca da justiça, relacionadas com as variáveis socioeconômicas e demográficas. Já o método empregado nesta pesquisa é de caráter quantitativo, descritivo e investigativo. Como análise estatística empregase o modelo logístico, compilado por meio do software livre R.

\section{RESULTADOS}

Mais de 2,5 milhões de brasileiros sofreram agressão física, pelo menos uma vez, entre 27 de setembro de 2008 e 26 de setembro de 2009. Dos quais, 5,4\% eram idosos. Ao se analisar esta estatística, veem-se, inicialmente, evidências de que a maior incidência deste crime é sofrida pelos jovens e adultos (pessoas com menos de 60 anos), contrariando a percepção popular de que a população idosa (pessoas com 60 anos ou mais) seria mais suscetível à vitimização (FIG. 1).

Figura 1 - Incidência do crime de agressão física por grupo etário segundo sexo, Brasil, 2009

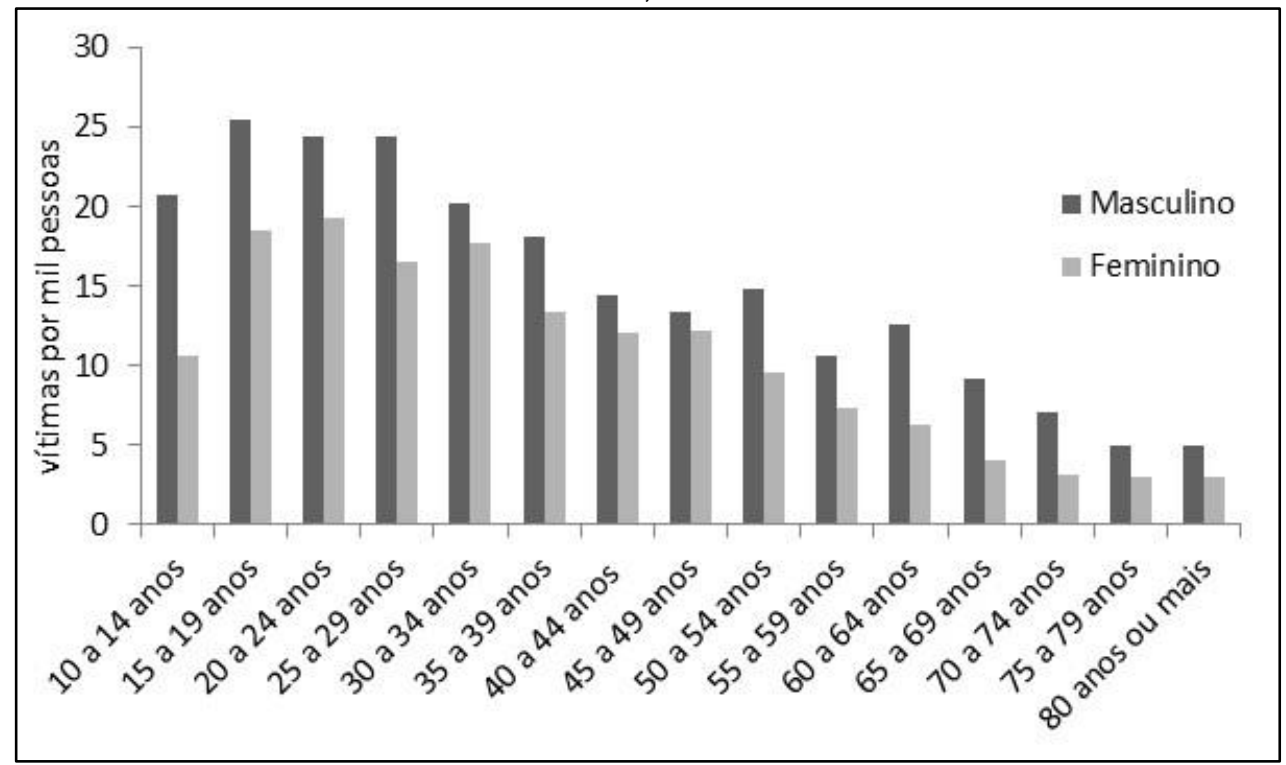

Fonte: Adaptado de IBGE (2009), Suplemento Vitimização e Acesso à Justiça.

Percebe-se que a incidência de agressão física contra a pessoa idosa encontra-se abaixo daquela declarada pela população não idosa, seja do sexo feminino, seja do sexo masculino. A única 
exceção é verificada na incidência de agressão física contra homens de 60 a 64 anos que, embora acima da violência praticada contra homens de 55 a 59 anos, encontra-se em patamar abaixo daqueles observados entre os demais homens jovens e adultos. A incidência se mostra aproximadamente decrescente com a idade, para ambos os sexos. O que mostra que mesmo diante da mítica fragilidade dos idosos, este estereótipo não os torna mais suscetíveis à vitimização, pelo menos do crime de agressão física.

Além disso, verifica-se que a agressão física praticada contra os homens é maior do que contra as mulheres, em todos os grupos etários, especialmente entre as idades de 15 e 29 anos. Pode-se pensar que alguns fatores contribuíram para essa ocorrência, como estilo de vida impulsivo entre os homens e ausência de suporte familiar, principalmente entre os jovens, e, até mesmo, subnotificação das denúncias entre as mulheres.

Ao se considerar o local de ocorrência das agressões físicas, verifica-se que há semelhanças, entre a população idosa e a população não idosa (FIG. 2). Entre idosos e não idosos, do sexo masculino, o local mais comum dessas ocorrências é a via pública, diferentemente das idosas e não idosas, do sexo feminino, que se tornam vítimas na própria residência ou na residência de terceiros. Provavelmente, isso se deve ao resultado da combinação: locais de maior conflito e desigualdade de força física.

Figura 2 - Distribuição do crime de agressão física entre idosos e não idosos, por sexo, segundo o local da última ocorrência, Brasil, 2009

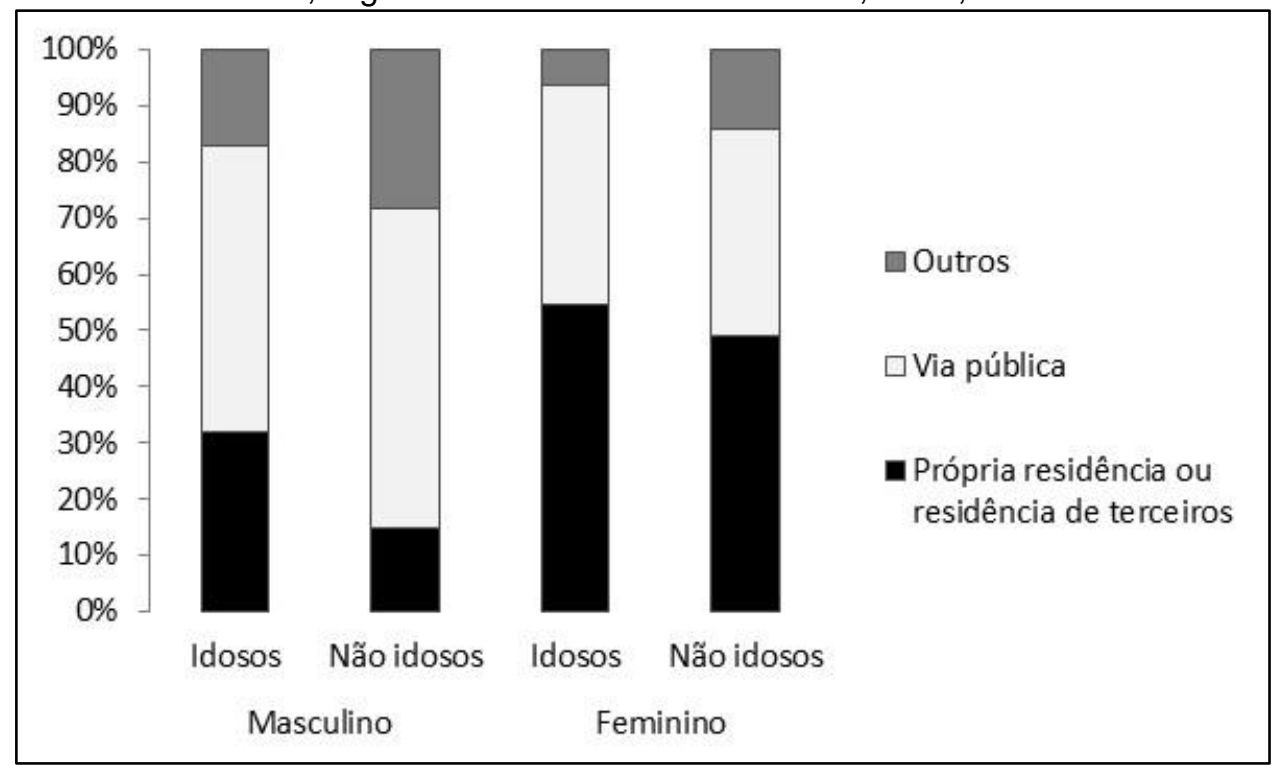

Fonte: Adaptado de IBGE (2009), Suplemento Vitimização e Acesso à Justiça.

O crime de agressão física, com certa limitação, permite estabelecer algumas características do agressor (FIG. 3). A maioria das vítimas femininas, incluindo idosas e não idosas, declarou sofrer agressão física de parente ou pessoa conhecida, seguido por cônjuge ou ex-cônjuge, corroborando 
com a estatística observada, anteriormente, na FIG. 2, em que os prováveis agressores são pessoas próximas, corresidentes ou indivíduos que frequentam o domicílio das vítimas, como pais, filhos, parceiros e cuidadores. Diferentemente, as vítimas masculinas, sejam idosos ou não idosos, declararam, em sua maioria, ter sofrido agressão por parte de pessoa desconhecida, policial ou segurança privada, confirmando, mais uma vez, a relação com o local da ocorrência.

Figura 3 - Distribuição do crime de agressão física entre idosos e não idosos, por sexo, segundo o agressor da última ocorrência, Brasil, 2009

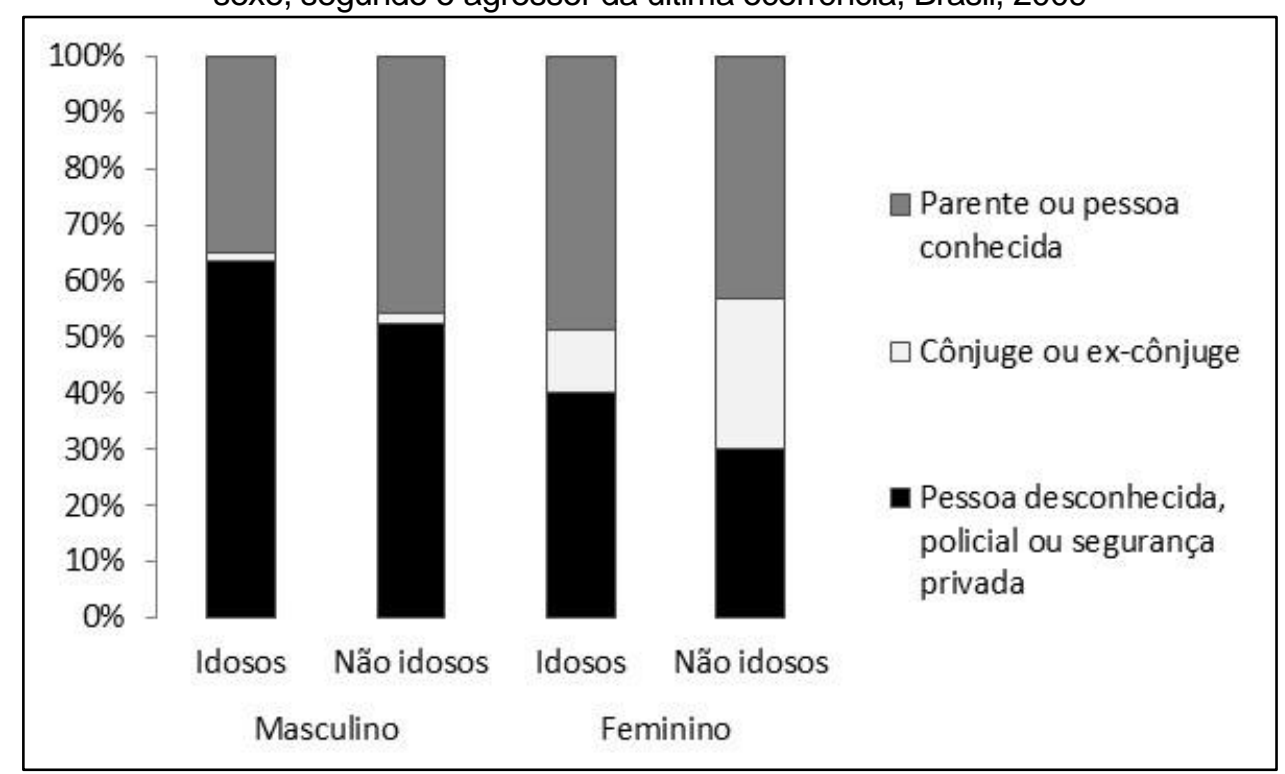

Fonte: Adaptado de IBGE (2009), Suplemento Vitimização e Acesso à Justiça.

Em relação à denúncia da última agressão física sofrida, somente, 44\% da população vitimada procurou a polícia, dos quais, somente, $87 \%$ registrou a ocorrência (índice aproximadamente idêntico para homens e mulheres, idosos ou não). Os motivos mais apontados pela população feminina, pelos quais não procurou a polícia após a ocorrência do último crime, refletem a ambiguidade psicológica vivida por pessoas que sofrem violência dentro de seus domicílios (TAB. 1). O medo de represália por parte do agressor e o receio de envolver a polícia refletem o medo de sofrer mais agressões e o medo de perder o agressor do seu meio social, tanto para idosas quanto para não idosas. Ao se analisar os motivos pelos quais a população masculina, vítima de agressão física, não procurou a polícia (TAB. 1), percebe-se que a população idosa e a população não idosa, apesar de suas particularidades, pouco se distinguem apresentando justificativas típicas de pequenos conflitos, como resolveu sozinho e não era importante. 
Tabela 1 - Distribuição percentual da população idosa e não idosa segundo o principal motivo pelo qual não procurou a polícia após a última agressão, por sexo, Brasil - 2009

\begin{tabular}{lcccc}
\hline \multirow{2}{*}{ Motivos } & \multicolumn{2}{c}{ \% Homem } & \multicolumn{2}{c}{$\%$ Mulher } \\
\cline { 2 - 5 } & Idoso & Não idoso & Idosa & Não idosa \\
\hline Falta de provas & 10,1 & 6,6 & 18,6 & 6,7 \\
Não era importante & 21,0 & 20,8 & 15,7 & 13,6 \\
Não acreditava na polícia & 24,4 & 13,4 & 4,8 & 11,6 \\
Não queria envolver a polícia & 5,9 & 15,1 & 17,3 & 19,7 \\
Medo de represália & 16,2 & 15,2 & 19,0 & 18,7 \\
Recorreu a terceiros & 4,2 & 4,9 & 2,5 & 4,6 \\
Resolveu sozinho & 16,4 & 20,3 & 13,8 & 18,8 \\
Outro & 1,6 & 3,9 & 8,3 & 6,2 \\
\hline
\end{tabular}

Fonte: Adaptado de IBGE (2009), Suplemento Vitimização e Acesso à Justiça.

As análises estatísticas baseadas na autodeclaração da população vítima e não vítima do crime de agressão física, até então, não indicaram indícios de maior vitimização dos idosos, comparativamente à população não idosa. O que pode sugerir que a formalização das ocorrências pelas autoridades é seletiva, provocando a sensação popular de que os idosos são as maiores vítimas de agressão física. De fato, o percentual da população vitimada, da qual a polícia não quis fazer o registro da ocorrência de agressão física, é menor entre as idosas (4,4\%), seguida pelos idosos $(19,4 \%)$, pelos não idosos $(20,4 \%)$ e, por fim, pelas não idosas $(25,8 \%)$. Isso pode ser pelo fato de que a vítima (geralmente não idosa) registra a ocorrência e, logo em seguida, retira a queixa, provocando constrangimentos às autoridades.

Os resultados do modelo logístico, apresentados na TAB. 2, mostram que as chances de uma mulher ser vítima de agressão física são menores que as chances de um homem. Embora a violência doméstica se caracterize por atos de agressão física, acreditamos que a violência praticada nas ruas, geralmente entre os homens, seja algo mais frequente.

Tabela 2 - Análise logística da razão de chance de sofrer agressão física, segundo variáveis sócio, econômico e demográficas, Brasil - 2009

\begin{tabular}{llll} 
& & Continua... \\
\hline Variáveis & Categorias & Chance & P-valor \\
\hline Intercepto & & $0,07^{*}$ & $<2 \mathrm{e}-16$ \\
\hline É idoso? & Não (referência) & & \\
& Sim & $0,43^{* *}$ & $<2 \mathrm{e}-16$ \\
\hline Sexo & $\begin{array}{l}\text { Masculino (referência) } \\
\text { Feminino }\end{array}$ & $0,74^{* *}$ & $<2 \mathrm{e}-16$ \\
\hline
\end{tabular}


Tabela 2 - Análise logística da razão de chance de sofrer agressão física, segundo variáveis sócio, econômico e demográficas, Brasil - 2009

\begin{tabular}{llll}
\hline Variáveis & Categorias & Chance & P-valor \\
\hline Situação do domicílio & Urbano (referência) & & \\
& $\begin{array}{l}\text { Rural } \\
\text { Raça/cor }\end{array}$ & $0,48^{* *}$ & $<2 \mathrm{e}-16$ \\
\hline & $\begin{array}{l}\text { Branco (referência) } \\
\text { Não branco }\end{array}$ & $1,25^{* *}$ & $1.05 \mathrm{e}-13$ \\
\hline É pessoa de referência? & Não (referência) & & \\
& Sim & $1,04^{* *}$ & 0,0437 \\
\hline Status do trabalho & Ativo (referência) & & \\
\hline Renda (rendimento domiciliar per capita) & $0,61^{* *}$ & $<2 \mathrm{e}-16$ \\
\hline Escolaridade (anos de estudo) & Não ativo & $0,86^{* * *}$ & $<2 \mathrm{e}-16$ \\
\hline
\end{tabular}

Fonte: Adaptado de IBGE (2009), Suplemento Vitimização e Acesso à Justiça.

Notas: * Não apresenta uma interpreção dentro do contexto; ** Chance de um indivíduo cujas características são apresentadas na tabela em relação à categoria de referência, ${ }^{* \star \star}$ Mudanças nas chances de um individuo em relação a cada unidade acrescida da varável.

As chances de vitimização por agressão física são menores e estatisticamente significativas para residentes da zona rural. Este fato, possivelmente, está relacionado com os guetos da marginalização, próprios das cidades. Entretanto, também é provável que este resultado esteja relacionado com a subdeclaração das ocorrências dos residentes da zona rural.

As pessoas de referência do domicílio não são mais ou menos vítimas que os demais moradores do domicílio, pois as chances de sofrer agressão física não são estatisticamente diferentes.

Os indivíduos economicamente ativos têm maiores chances de serem vítimas de agressão física. Contrariando, em parte, as chances explicadas pela renda. Neste caso, a renda e as chances de vitimização são inversamente relacionadas. Acredita-se que essa ambiguidade se dê porque a renda não é forte determinante da ocorrência desse crime ou porque não está bem declarada pela população. Além disso, a escolaridade mostra-se negativamente relacionada com a agressão física. Apesar de estatisticamente significativa, os níveis de escolaridade têm pouca influência nas chances de vitimização do crime.

Os resultados obtidos pelo modelo logístico apresentados na TAB. 2 indicam que as chances de idosos serem vítima de agressão física são menores que as chances de não idosos. Esta estimativa permite levantar algumas hipóteses. A primeira explicação é de que pode haver um viés na declaração da ocorrência de vitimização, em virtude da presença do agressor. A segunda, pode estar relacionada com a questão da incapacidade física e, principalmente, mental de delatar tais ocorrências. E, por último, apesar de crescente, a agressão física contra a pessoa idosa realmente não incide em proporção semelhante à população jovem e adulta. 
Infelizmente, cabe destacar que os dados não permitem avaliar a gravidade dos crimes ou a competência dos criminologistas em julgá-los, sugerindo futuros estudos que esclareçam as diferenças entre a população idosa e não idosa, bem como entre homens e mulherees no que se refere a essas lacunas.

\section{CONSIDERAÇÕES FINAIS}

No Brasil, o Estatuto do Idoso, aprovado em 2003, pode ser considerado um marco na história brasileira como conquista de cidadania. Este estatuto prevê os direitos dos idosos e as punições a quem os violarem, proporcionando maior qualidade de vida a essa população. Apesar de sua visibilidade, o estatuto do idoso não era, até então, o único dispositivo legal que garantia os direitos dos cidadãos com idade acima de 60 anos. Ao instituir penas severas para quem desrespeitar ou abandonar cidadãos da terceira idade, o estatuto tornou-se mais abrangente que a Política Nacional do Idoso, lei de 1994, que dava garantias à terceira idade. E reafirmou o que a Constituição Brasileira de 1988, em seu artigo 5º, já assegurava: todos os cidadãos brasileiros (incluindo idosos) são iguais perante a lei, sem distinção de qualquer natureza, com garantia a inviolabilidade do direito à vida, à liberdade, à igualdade, à segurança e à propriedade.

Isto leva a crer que, se a percepção com relação à vitimização do idoso se destaca como preocupação pública, não é pelo fato de ser resguardada por uma legislação nova, mas pelos novos modos de vida e novos comportamentos da população, principalmente a idosa, em busca de justiça. Com rendimentos e escolarização mais elevados, os idosos tornam-se, sem dúvidas, classe mais empoderada e consciente de seus direitos. Contudo, estas mesmas características também os tornam alvos de vitimização, diferenciando ou persistindo, pela questão de gênero, observada em outras idades.

Ao se traçar o perfil das vítimas de agressão física, incluindo as características relevantes de tais ocorrências criminais, bem como algumas questões comportamentais associadas a esses eventos, observou-se que pouco mais de $5 \%$ dos brasileiros que sofreram agressão física eram idosos, denotando pequena, mas não desprezível, chance de se tornarem vítimas deste crime. Apesar disso, idosos e não idosos guardam semelhanças quando analisados segundo o sexo. A maioria das vítimas femininas declarou sofrer agressão física de parentes ou pessoas conhecidas, na própria residência ou na residência de terceiros, já a maioria das vítimas masculinas declarou sofrer agressão física de pessoa desconhecida em via pública.

E, ainda, no que concerne ao acesso à justiça, ao se conhecer os tipos de conflitos vivenciados pela população e como as pessoas tentaram resolvê-los, percebeu-se que, após a 
última agressão física, menos da metade da população vitimada procurou a polícia. Dos quais, nem todos registraram a ocorrência. Os motivos mais apontados pela população feminina foram o medo de represália por parte do agressor e o receio de envolver a polícia; já entre a população masculina as justificativas mais apontadas são: resolveu sozinho e não era importante. O que também denota a falta de credibilidade na eficiência do sistema de segurança nacional.

Em termos de políticas públicas, isso significa que a criação de delegacias dos idosos não se justifica em virtude da demanda. Já que a demanda de outros segmentos da sociedade é maior, como é o caso dos crimes cometidos contra homens jovens. Assim sendo, o objetivo das políticas públicas, atualmente, deveria ser a inclusão dos idosos e das idosas nas políticas de prevenção, controle e promoção de justiça de crimes contra cidadãos, com enfoque de gênero, pois há perceptível semelhança comportamental entre idosos e não idosos, e idosas e não idosas. Dessa forma, a pessoa idosa, como qualquer cidadão, teria seus direitos e sua integridade garantidos, sem a necessidade de comprovação de altos índices de criminalidade, visto que os criminologistas atenderiam à sociedade com base na sua real demanda.

\section{REFERÊNCIAS}

BROGDEN, Michael; NIJHAR, Preeti. Abuse versus crime in criminological history. In: Crime, abuse and the elderly. Routledge, Cap.1, p. 7-23, 2000a.

The mythologies of elderly victimisation. In: Crime, abuse and the elderly. Routledge, Cap.2, p. 24-36, 2000b.

CRYSTAL, Stephen. Social policy and elder abuse. In: PILLEMER, Karl A.; WOLF, Rosalie S. (Ed.). Elder abuse: Conflict in the family. Greenwood Publishing Group, p. 331-340, 1986.

FALEIROS, Vicente P. Riscos de óbitos em pessoas idosas por causas externas. In: BERZINS, Marília V.; MALAGUTTI, William (Ed). Rompendo o silêncio: faces da violência na velhice. São Paulo: Editora Martinari, p.237-252, 2010.

INSTITUTO BRASILEIRO DE GEOGRAFIA E ESTATíSTICA (IBGE). Pesquisa Nacional por Amostra de Domicílios (PNAD). 2009. Acesso: 09/07/2018. [Visualizar]

NOVO, Ana Lúcia M. S.; LOPES, Ruth G. C. O outro lado da moeda: velhos violentos. In: BERZINS, Marília V.; MALAGUTTI, William (Ed). Rompendo o silêncio: faces da violência na velhice. São Paulo: Editora Martinari, p. 237-252, 2010.

PAYNE, Brian K. The young get older and the older get victimized. In: Crime and elder abuse: An integrated perspective. Charles C. Thomas Publisher, Cap.1, p. 3-29, 2005.

REINHARZ, Shulamit. Loving and Hating One's Elders: Twin Themes in Legend and Literature. In: PILLEMER, Karl A.; WOLF, Rosalie S. (Ed.). Elder abuse: Conflict in the family. Greenwood Publishing Group, p. 25-48, 1986. 
SILVA, Cirlene Francisca Sales, DIAS, Cristina Maria de Souza Brito. Violência Contra Idosos na Família: Motivações, Sentimentos e Necessidades do Agressor. Psicologia: Ciência e Profissão, jul/set., v. 36, n 3, p. 637652, Brasília-DF, 2016. Google Ecrosset

WALLACE, Robert B.; BONNIE, Richard J. (Ed.). The occurrence of elder mistreatment. In: Elder Mistreatment: Abuse, Neglect, and Exploitation in an Aging America. National Academies Press, Cap.4 , p.71-87, 2003a.

Risk factor for elder mistreatment. In: Elder Mistreatment: Abuse, Neglect, and Exploitation in an Aging America. National Academies Press, Cap.4, p. 88-103, 2003b. 